\title{
Comparative hepatitis A seroepidemiology in 10 European countries
}

S. KURKELA ${ }^{1,2}$, R. PEBODY ${ }^{1 *}$, G. KAFATOS ${ }^{1}$, N. ANDREWS ${ }^{1}$, C. BARBARA $^{3}$, B. BRUZZONE ${ }^{4}$, D. BUTUR ${ }^{5} \dagger$, S. CAPLINSKAS ${ }^{6}$, I. DAVIDKIN ${ }^{7}$,

A. HATZAKIS ${ }^{8}$, W. HELLENBRAND ${ }^{9}$, L. M. HESKETH ${ }^{1}$, A. NARDONE ${ }^{1}$, V. NEMECEK ${ }^{10}$, A. PISTOL ${ }^{11}$, Z. SOBOTOVÁ ${ }^{12}$, R. VRANCKX ${ }^{13}$ AND

C. G. ANASTASSOPOULOU ${ }^{8}$

${ }^{1}$ Health Protection Agency, Health Protection Services, Colindale, London, UK; ${ }^{2}$ European Public Health Microbiology Fellowship Programme (EUPHEM), Stockholm, Sweden; ${ }^{3}$ St Luke's Hospital, G'Mangia, Malta; ${ }^{4}$ Department of Health Sciences, University of Genova, Genova, Italy; ${ }^{5}$ National Reference Centre for Viral Hepatitis, National Centre for Expertise in Medical Microbiology, National Institute for Research and Development in Microbiology and Immunology 'Cantacuzino,' Bucharest, Romania; ${ }^{6}$ Center for Communicable Diseases and AIDS, Vilnius, Lithuania ; ${ }^{7}$ National Institute for Health and Welfare, Helsinki, Finland; ${ }^{8}$ National Retrovirus Reference Centre, Department of Hygiene and Epidemiology, University of Athens Medical School, Athens, Greece; ${ }^{9}$ Robert Koch-Institute, Berlin, Germany; ${ }^{10}$ National Institute of Public Health, Prague, Czech Republic; ${ }^{11}$ Institutul de Sanatate Publica Bucuresti, Bucharest, Romania; ${ }^{12}$ National Laboratory for Poliomyelitis and Viral Hepatitis, Public Health Authority of the Slovak Republic, Bratislava, Slovakia;

${ }^{13}$ Institute of Public Health, Brussels, Belgium

Received 3 August 2011; Final revision 12 November 2011; Accepted 21 December 2011; first published online 25 January 2012

\section{SUMMARY}

The WHO recommends hepatitis A virus (HAV) immunization according to level of transmission and disease burden. We aimed to identify susceptible age groups by standardized serosurveys to inform HAV vaccination policy in participating countries: Belgium, Czech Republic, England, Finland, Germany, Italy, Lithuania, Malta, Romania, and Slovakia. Each country tested national serum banks ( $n=1854-6748)$, collected during 1996-2004, for anti-HAV antibodies. Local laboratory results were standardized to common units. Forty-one per cent of those aged $<30$ years and $6 \%$ of those aged $\geqslant 30$ years were susceptible to HAV in Romania; compared to 70-94\% and 26-71\%, respectively, elsewhere. Romania reported high HAV incidence in children and young adults. Other countries reported HAV disease primarily in older risk groups. The results suggest low level of HAV transmission in most of Europe. Romania, however, appeared as an area with intermediate transmission. Vaccination of risk groups in countries with high susceptibility of young and middle-aged adults needs to be continued.

Key words: Epidemiology, Europe, hepatitis A, hepatitis A antibodies, incidence, serology, vaccination.

\footnotetext{
* Author for correspondence: Dr R. Pebody, Health Protection Agency, Health Protection Services, 61 Colindale Avenue, Colindale, London NW9 5EQ, UK.

(Email: richard.pebody@hpa.org.uk)

$\dagger$ Deceased.
} 


\section{INTRODUCTION}

Hepatitis A virus (HAV) is a non-enveloped positivestranded RNA virus of the genus Hepatovirus in the family Picornaviridae. HAV transmission occurs mainly through the faecal-oral route, and rarely through blood-to-blood contact. In countries with low seroprevalence, specific risk groups for HAV infection include, e.g. travellers (to endemic regions), healthcare workers, men who have sex with men (MSM), injecting drug users (IDUs), and persons receiving blood products. In children aged $<5$ years, HAV infection is usually inapparent, whereas most adults present with symptoms, with the severity of the disease increasing with age [1]. The laboratory diagnosis of HAV is primarily based on serology. HAV $\mathrm{IgG}$ antibodies persist throughout life, and are a marker of past immunity. The available inactivated HAV vaccines are safe and provide long-term protection. Mathematical modelling predicts antibody persistence for more than 25 years in over $95 \%$ of vaccine recipients [2]. No specific antiviral treatment is available for HAV infection.

The age-specific seroprevalence and incidence of HAV is known to vary geographically. The data available on age-specific susceptibility to HAV and average age of infection in Europe are incomplete and geographically diverse; for many European countries no seroepidemiological data are available at all. An early report comparing seroepidemiological data from seven European countries indicated higher HAV seroprevalence in the south of Europe compared to the north [3]. Since then, improvements in socioeconomic and hygienic conditions [4] as well as preventive interventions, have led to increasing susceptibility to HAV in children and young adults throughout many parts of Europe, as reported by sporadic seroepidemiological studies by individual European countries [5-11]. Southern Europe is still estimated to have a high overall HAV seroprevalence, although seroprevalence in young adults is declining [12].

The position of the World Health Organization (WHO) on HAV vaccines emphasizes that the degree of HAV transmission in a particular country should guide vaccination policy [13]. In highly endemic countries, large-scale immunization should not be undertaken, as most children acquire the (usually asymptomatic) infection before the age of 10 years, and subsequently clinical HAV is rare. In countries with low endemicity and with high rates of disease in specific high-risk groups, such as IDUs and travellers, vaccination should be targeted primarily to these groups. According to the WHO position, it is the areas with intermediate endemicity, where transmission occurs primarily from person to person in the general community and often with periodic outbreaks, where widespread vaccination programmes should be considered, as in these countries many individuals escape childhood infection and are exposed to clinical HAV as adults [13].

In this study the serological results were standardized to produce comparable, age-specific seroprevalence estimates of HAV across Europe. Using these data, the aims of the study were to identify susceptible age groups and to investigate how these relate to disease incidence data, in order to inform HAV vaccination policy in the 10 participating countries.

\section{METHODS}

\section{Serum collection}

Ten countries participating in the European SeroEpidemiology Network 2 (ESEN2) project tested their national serum banks for total antibodies to HAV (anti-HAV). Specimens were collected between 1996 and 2004, either as residual sera remaining after routine laboratory testing (7/10 countries), or by population-based random sampling (3/10 countries) (Table 1). Ethical approval of the study protocol was sought from the appropriate national authorities according to national guidelines.

The project guidelines called for an even distribution between males and females of sera that were also required to be geographically representative for each country. The guidelines further recommended the testing of $>3000$ specimens from all age groups, of which two-thirds were to be derived from those aged $<20$ years. The age-specific numbers were defined at the start of the ESEN2 project. Table 1 shows the number and age distribution of the collected sera for each country. Sample sizes smaller than reommended were tested in the Czech Republic, Lithuania, and Malta. Not all age groups were represented in the serum panels of Germany and Lithuania.

\section{Organizational analysis: vaccine programme and hepatitis A incidence}

All national representatives completed a standardized electronic questionnaire regarding the HAV 


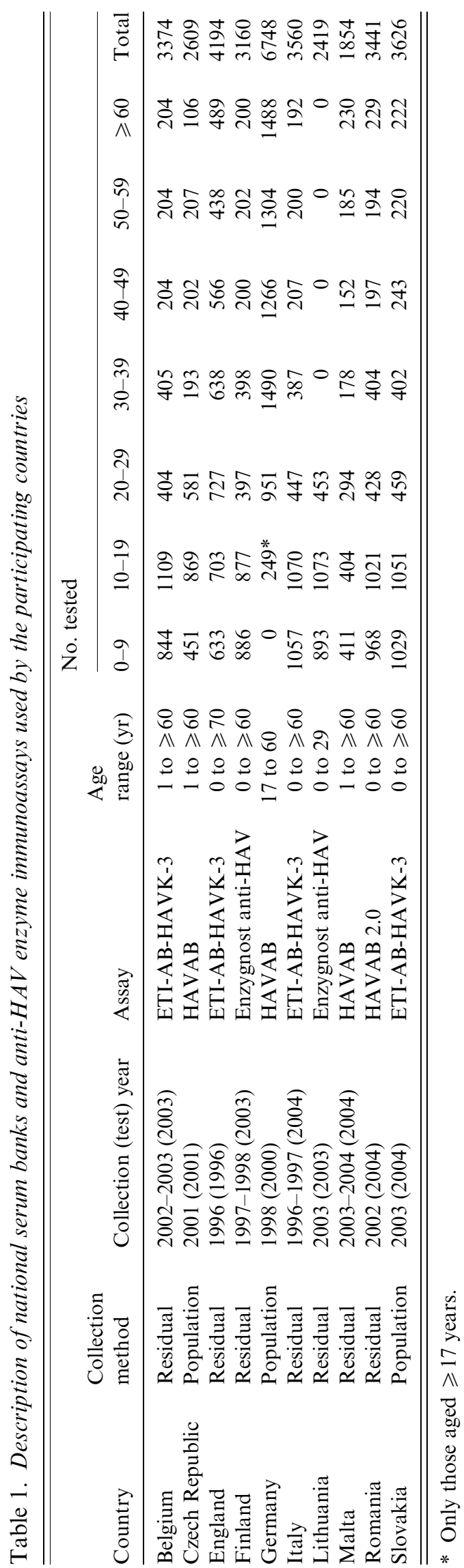

vaccination programme in effect in each participant country in March 2002 (Table 2). Disease incidence by age since 1970 was requested as well as information on whether the reported incidence represented laboratory-confirmed cases or clinical notifications. Updated information was requested in 2010.

\section{Assay standardization}

The procedure followed to standardize the antibody results has been described in detail elsewhere [14, 15]. Briefly, a standardization panel of 150 sera was developed by a designated reference laboratory (the National Retrovirus Reference Center, University of Athens Medical School, Greece), to include specimens with antibody titres ranging from negative and equivocal (low positive) to high positive. This panel was tested by the participating national laboratories for total anti-HAV antibodies using assays of their choice. Each country's results were subsequently regressed against those of the reference laboratory, obtained with HAVAB 2.0 quantitative test on the AxSYM system (Abbott Laboratories, USA). The standardization equations were then used to convert titres from local (national) tests to standard units. The $R^{2}$ (the square of the multiple correlation coefficient) was used to evaluate the standardization of the assays $[14,15]$. For situations where the proportion of the variability in the data explained by the regression model was too low, the equations were deemed inefficient and were excluded from the study.

Since the main serum banks of Germany and England had already been tested over a year before the distribution of the standardization panel (Table 1), an alternative method termed 'back-standardization' described in detail elsewhere [15] was undertaken. In brief, a subset of about 150 titre-stratified (negative, low positive, positive) specimens from the country's main serum bank was tested by the reference laboratory with its established assay. Standardization was then performed as described above after a regression analysis on the two generated datasets [14].

\section{Main serum bank testing and data analysis}

Each country used the same assay to test the standardization panel and the main serum banks. After the main bank results were transformed into standardized reference laboratory units, they were reclassified as negative or positive, using the reference laboratory cut-offs. 
Table 2. HAV vaccination policy at the time of specimen collection in the participating countries

\begin{tabular}{|c|c|c|c|c|c|c|c|c|c|c|}
\hline \multirow[b]{3}{*}{ Country } & \multicolumn{9}{|c|}{ Risk group } & \multirow[b]{3}{*}{$\begin{array}{l}\text { Outbreak } \\
\text { control }\end{array}$} \\
\hline & \multicolumn{2}{|c|}{ Professional } & \multicolumn{4}{|c|}{ Lifestyle } & \multicolumn{3}{|c|}{ Medical condition } & \\
\hline & $\mathrm{HCW}$ & Other* & IDU & MSM & Travellers & Other & $\begin{array}{l}\text { Chronic liver } \\
\text { disease }\end{array}$ & Haemophilia & Other & \\
\hline Belgium & $\checkmark$ & $\checkmark$ & & & $\checkmark$ & & & $\checkmark$ & & $\checkmark$ \\
\hline Czech Republic & & & & & & & & & & $\checkmark$ \\
\hline England & & $\checkmark$ & $\checkmark$ & $\checkmark$ & $\checkmark$ & & $\checkmark$ & $\checkmark$ & & $\checkmark$ \\
\hline Finland & & $\checkmark$ & $\checkmark$ & & $\checkmark$ & & $\checkmark$ & $\checkmark$ & & $\checkmark$ \\
\hline Germany & $\checkmark$ & $\checkmark$ & & $\checkmark$ & $\checkmark$ & & $\checkmark$ & $\checkmark$ & $\sqrt{ } \S$ & $\checkmark$ \\
\hline Italy & & $\checkmark$ & $\checkmark$ & & $\checkmark$ & $\checkmark \dagger$ & $\checkmark$ & $\checkmark$ & $\sqrt{ } \S$ & $\checkmark$ \\
\hline Lithuania & & & & $\checkmark$ & & & & & & $\checkmark$ \\
\hline Malta & $\checkmark$ & $\checkmark$ & & & $\checkmark$ & $\checkmark \dagger$ & & & & \\
\hline Romania & & & & & & & & & & $\checkmark$ \\
\hline Slovakia & $\checkmark$ & $\checkmark$ & $\checkmark$ & & $\checkmark$ & $\sqrt{ } \$$ & $\checkmark$ & & & $\checkmark$ \\
\hline
\end{tabular}

HCW, Healthcare worker; IDU, injecting drug user; MSM, men who have sex with men.

* Including, e.g. laboratory workers at risk, sewage workers, workers in institutions for the care of mentally or behaviourally disabled, workers in childcare institutions, canal workers, food handlers, workers in hospital laundry, people who work with primates.

$\dagger$ Military and diplomatic staff posted abroad.

f Children living in unhygienic conditions.

$\S$ Non-immune patients with chronic hepatitis B or C virus infection.

\section{RESULTS}

Standardization was successful for the ten countries included in this study: Belgium, Czech Republic, England, Finland, Germany, Italy, Lithuania, Malta, Romania, and Slovakia [14]. The susceptibility to HAV decreased in the older age groups in all participating countries (Table 3 ). The overall susceptibility was lowest in Romania and highest in Finland. In the $\geqslant 30$ years age group, $6 \%$ were susceptible in Romania, $26 \%$ in Malta, $28 \%$ in Italy, $41 \%$ in Slovakia, $46 \%$ in Germany, $48 \%$ in England, $50 \%$ in Belgium, $54 \%$ in Czech Republic, and $71 \%$ in Finland. Data were missing for Lithuania. In the $<30$ years age group, $42 \%$ were susceptible in Romania, compared to $70-94 \%$ in the other countries (Table 3).

There was $>80 \%$ susceptibility throughout the $<50$ years age group in Finland; $<40$ years in Czech Republic; $<30$ years in Belgium, England, Germany, Italy, Slovakia, and $<10$ years in Lithuania and Malta. A $<40 \%$ susceptibility was seen throughout the $\geqslant 10$ years age group in Romania; $\geqslant 40$ years in Malta and Italy, $\geqslant 50$ years in Belgium, Czech Republic, England, Germany, Slovakia; and $\geqslant 60$ years in Finland. The median age of infection was lowest in Romania (10 years), and ranged from 35 to 56 years in the other countries (not calculated for
Lithuania due to missing data in older age groups) (Table 3).

Figure 1 shows the seroprevalence of HAV in the participating countries by birth cohort. The seroprevalence fell below $20 \%$ in the birth cohorts of the early 1950s in Finland; mid-1960s in Czech Republic and Germany; late 1960s in Italy; mid-1970s in England and Slovakia; and early 1990s in Belgium and Malta. In Lithuania and Romania the seroprevalence was $>20 \%$ in all birth cohorts (data not available for those aged $>30$ years in Lithuania).

Table 3 shows the reported HAV incidence for all participating countries (when reported data were available). The highest incidence was reported in Romania (283/100 000). The incidence varied between $0 \cdot 3-54 / 100000$ population in the other countries (data for Lithuania unavailable).

Examining more closely Romania and Finland (Figs 2, 3), countries which represent the two extremes in this study, several differences can be observed. Romania showed an $\sim 70 \%$ seroprevalence in those aged $<1$ year; the seroprevalence in women of typical childbearing age (20-39 years) was $85 \%$ (data not shown), whereas in Finland, the respective seroprevalence was $6 \%$ and $5 \%$ (data not shown). In Romania, the lowest seroprevalence was seen in those aged 1-10 years, varying between $28 \%$ and $49 \%$, 


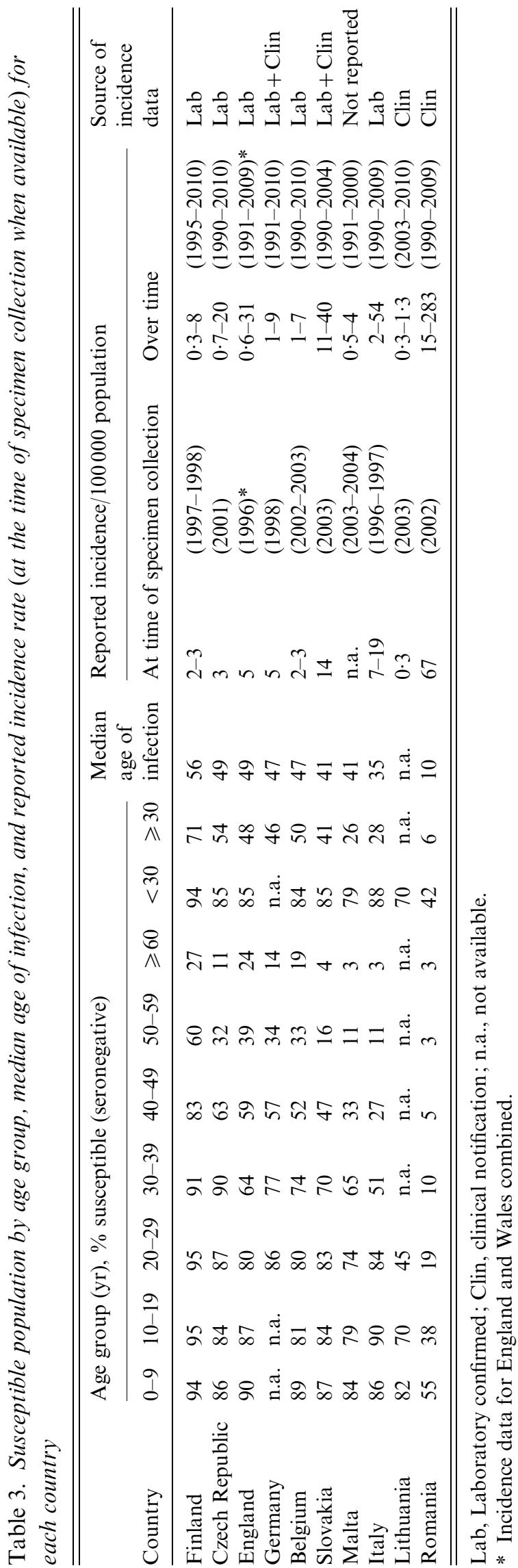

after which age the seroprevalence remained above $50 \%$, steeply increasing towards the older age groups, reaching $97 \%$ in those aged 50-59 years (Fig. 2). According to the data provided by the country for the ESEN2 project, in the specimen collection year 2002, the highest HAV disease incidence in Romania was in the 5-19 years age group (152-285/100000) (Fig. 2), whereas in the other participating countries the respective incidence remained $<60 / 100000$ (agespecific data from 2002 not available for Belgium, Lithuania, and Malta). In Finland, seroprevalence remained low throughout the $0-39$ years age groups, varying between $2 \%$ and $10 \%$, and thereafter increasing towards the older age groups, reaching $40 \%$ in the 50-59 years age group, and $73 \%$ in those aged $\geqslant 60$ years. According to the data from the Finnish infectious diseases registry, during the specimen collection years 1997-1998, the incidence was highest in those aged 10-39 years (4-6/100000) (Fig. 3a). In 2002, when an outbreak in IDUs was reported, the overall incidence was highest in those aged 15-34 years (12-22/100 000) (Fig. $3 a$ ). Comparing the overall incidence of the two countries over time, the incidence was 9-272 times higher in Romania than in Finland during 1988-2009, with a decreasing trend over time in Romania (Figs $2 b, 3 b$ ).

\section{DISCUSSION}

This comparative, population-based seroepidemiological study demonstrates that in most European countries included in this study, i.e. Belgium, Czech Republic, England, Finland, Germany, and Slovakia, there was a high susceptibility to HAV in children and young adults, and moderate susceptibility in older adults. In Malta and Italy, there was high susceptibility in children and young adults, but older adults showed low susceptibility. Romania differed from the other participating countries by showing a low overall susceptibility to HAV, and high disease incidence, particularly in children and young adults.

A major strength of this study is the direct comparability of the anti-HAV antibody test results between countries, which was achieved through the data standardization procedure. However, there are a number of limitations to this study. The serological tests used for the detection of anti-HAV antibodies do not distinguish between natural and vaccine immunity, and the seroprevalence data therefore represent both groups. Information was not available 
(a)

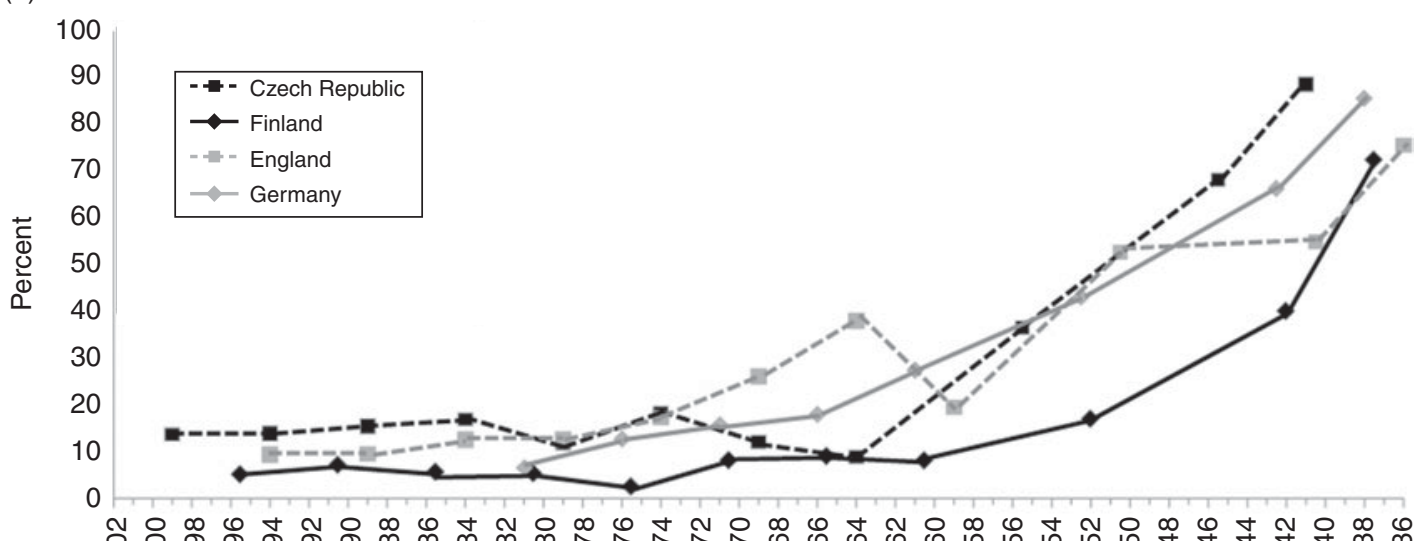

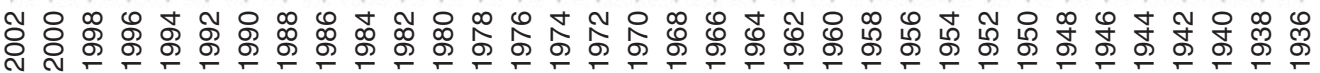

Birth year

(b)

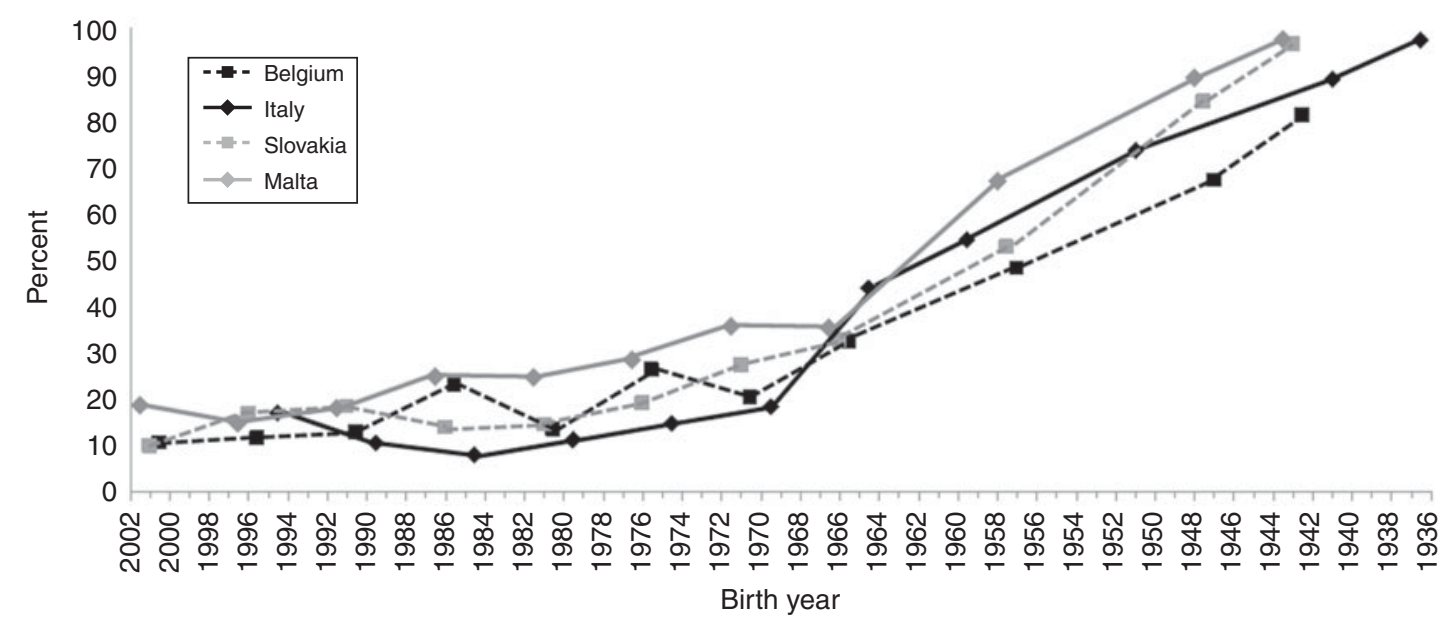

(c)

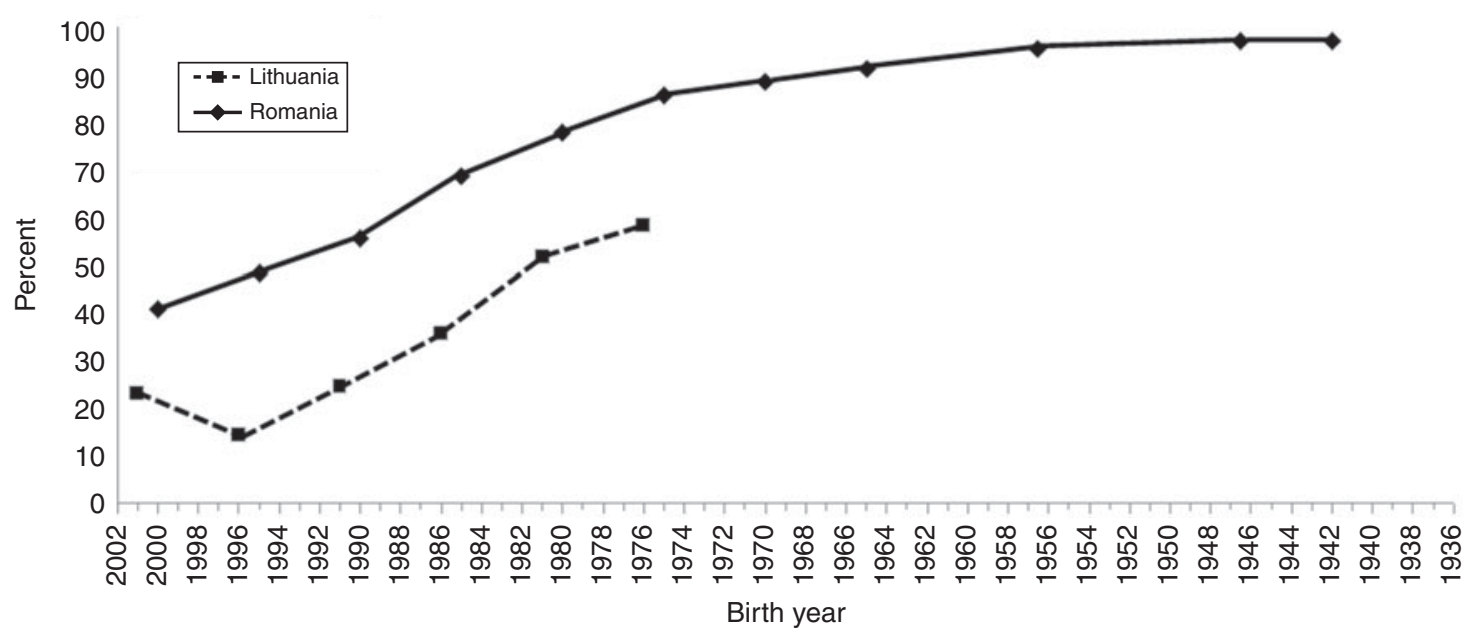

Fig. 1. Seroprevalence of HAV in the participating countries by birth cohort: (a) Czech Republic, Finland, Germany, England; (b) Belgium, Italy, Malta, Slovakia; $(c)$ Lithuania and Romania. The data in these panels are based on the following age groups: $0-4,5-9,10-14,15-19,20-24,25-29,30-34,35-39,40-49,50-59$, and $\geqslant 60$ years. The data points represent the median birth year of each group, except for the end points which represent the end point birth year and all those born before that. 

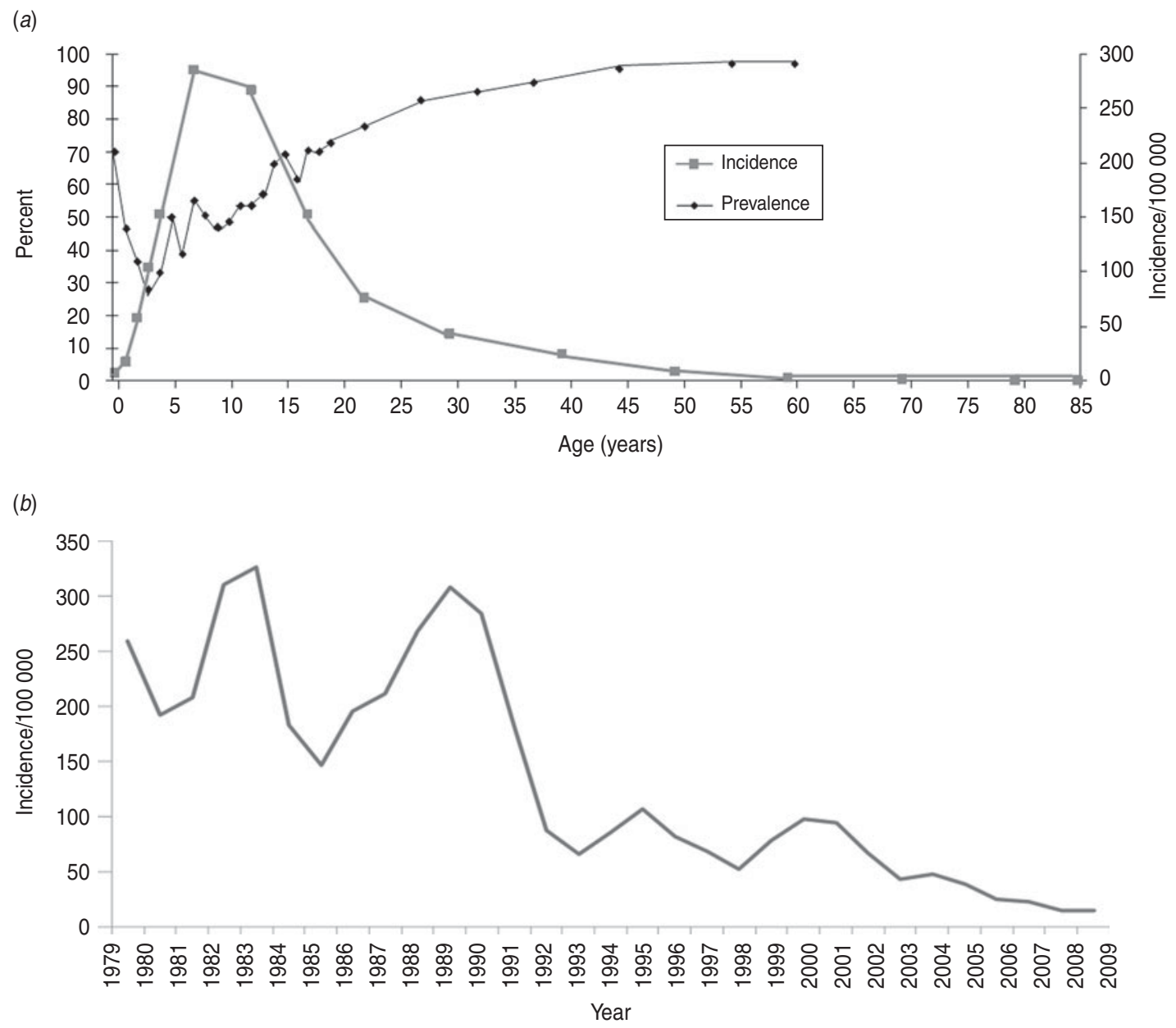

Fig. 2. Characteristics of HAV seroepidemiology in Romania. HAV seroprevalence in 2002 and age-specific incidence in (a) 2002, and (b) overall incidence over time. In panel $(a)$, the age-specific incidence data are based on the following age groups: $<1,1,2,3,4,5-9,10-14,15-19,20-24,25-34,35-44,45-54,55-65,65-74,75-84, \geqslant 85$ years, and the age-specific prevalence data are based on the following age groups: $0,1,2,3,4,5,6,7,8,9,10,11,12,13,14,15,16,17,18,19,20-24$, $25-29,30-34,35-39,40-49,50-59, \geqslant 60$ years. The data points represent the median age of each group, except for the end points, which represent the end point age and all those older than that.

with regard to vaccine uptake. Furthermore, the data were collected in different years in the participating countries, which complicate their temporal comparability. Not all age groups were represented in all of the countries. Although the standardization procedure was generally successful, it was considered unsatisfactory for the countries that had to be excluded [14]. It is also possible that the seroprevalence profiles in some of the countries may have changed since the collection of the data for this study. Furthermore, the information collected from the countries on reported cases was in some cases incomplete and was based on clinical and laboratory-based reporting using different case definitions, and therefore caution is advised when interpreting and comparing incidence estimates between countries.
Many of the participating countries have previously reported sporadic HAV seroprevalence data in the literature $[5-11,16,17]$. The previously available data are in line with the present study. However, for Lithuania, Malta, Romania, and Slovakia, almost no internationally published information was available on HAV seroprevalence, and for other countries the data were not comparable to each other. This study provides new insights into the comparative seroepidemiology of HAV in these countries.

Analysis of HAV seroprevalence by birth cohort in each participating country (Fig. 1) showed that in Finland and England, endemic circulation of HAV continued until the early 1960s. Endemic circulation in Germany and Czech Republic persisted until the mid-1960s, which was also true for Malta, but with a 
(a)
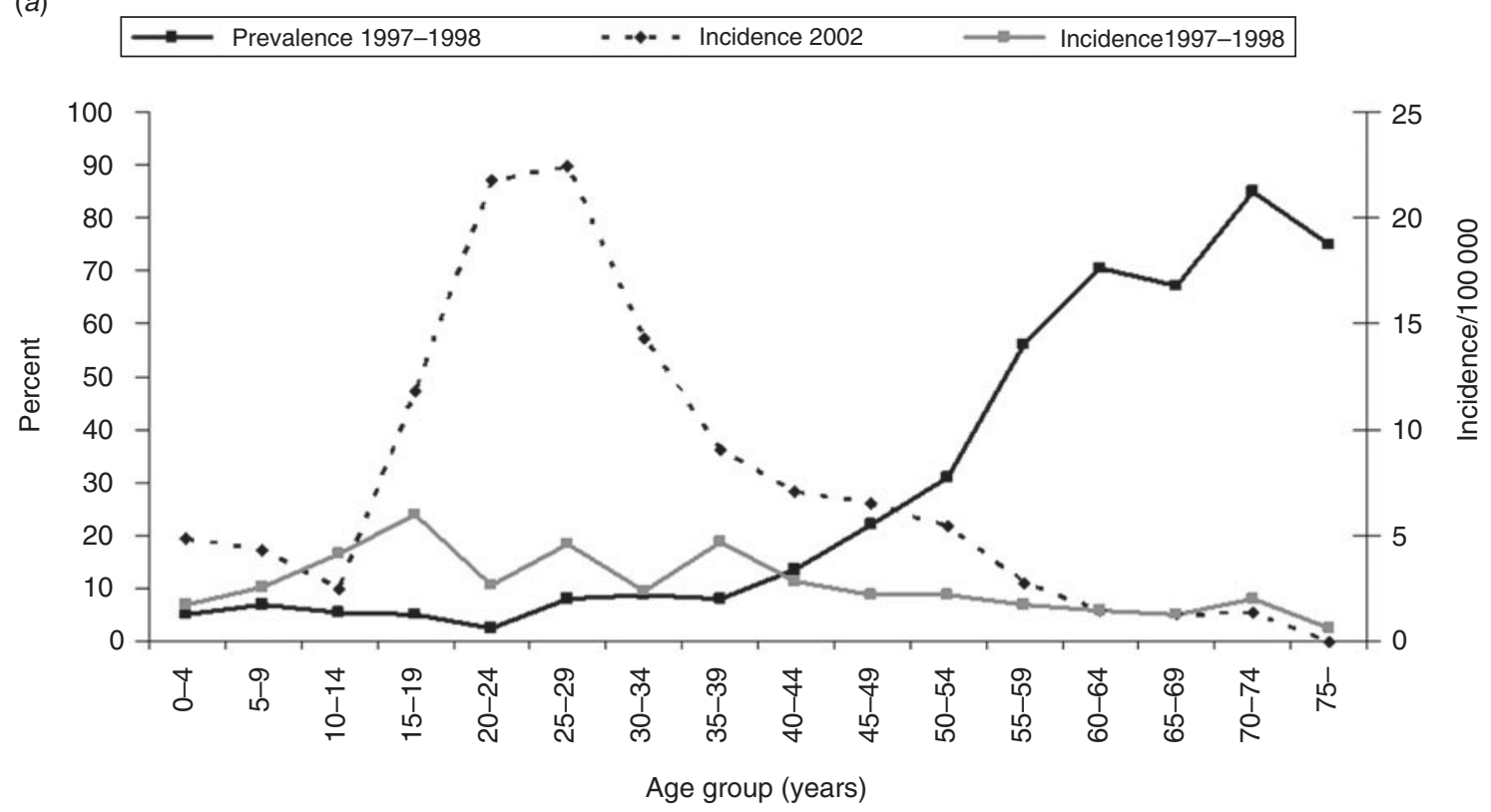

(b)

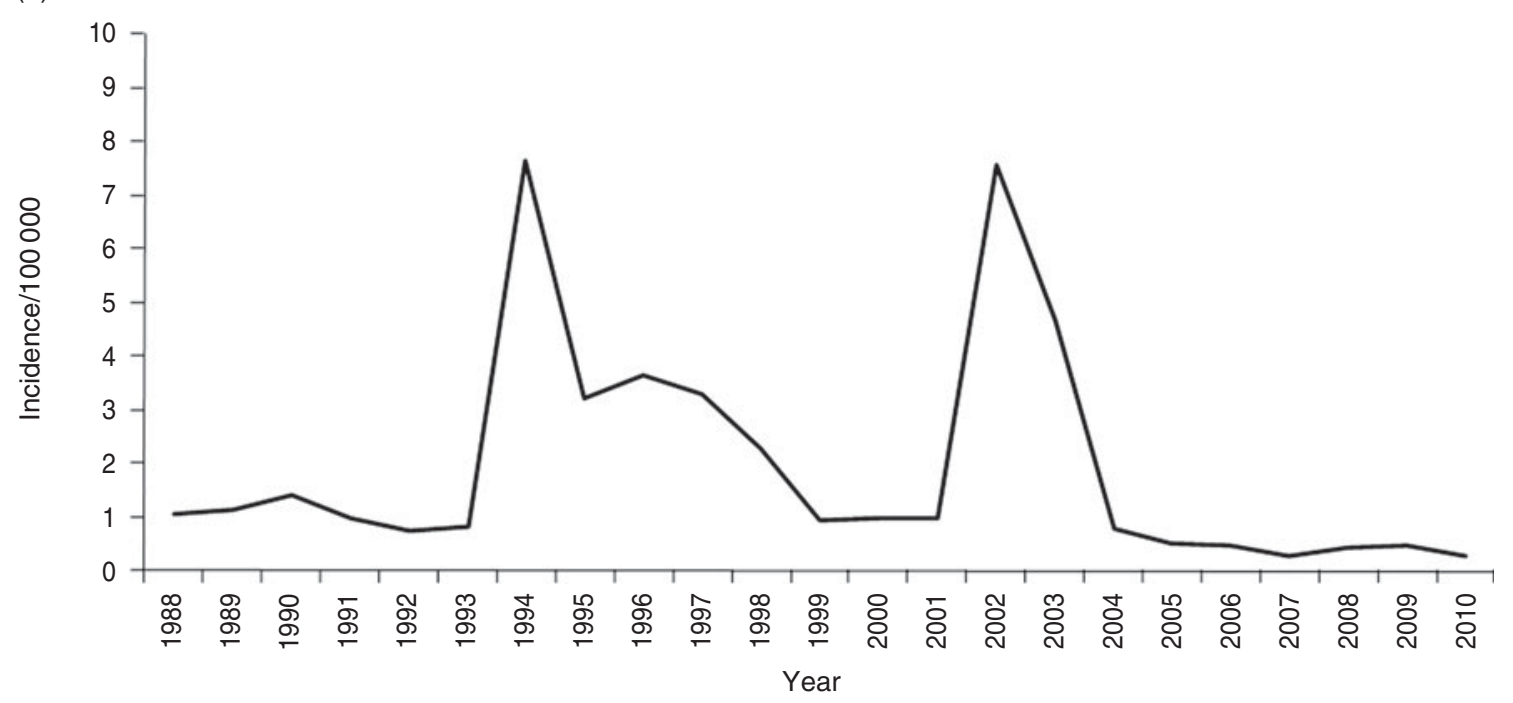

Fig. 3. Characteristics of HAV seroepidemiology in Finland. (a) HAV seroprevalence in 1997-1998, and age-specific incidence in 1997-1998 (combined) and in 2002 (when HAV outbreak in intravenous drug users occurred in Finland. (b) Overall incidence over time.

higher seroprevalence profile throughout the birth cohorts. In contrast, in Belgium, Italy, and Slovakia, the endemic circulation continued well until the end of 1960s. In Lithuania, a trend towards increasing seroprevalence was noted after age 10 years (birth cohort 1993); however, data were not available for those aged $>30$ years. The very high seroprevalence across all birth cohorts clearly distinguished the seroprevalence profile of Romania from the other participating countries.
The HAV seroprofiles in birth cohorts to some extent appear to reflect changes in hygienic and socioeconomic conditions in different countries over time. Indicative of historic transmission, all participating countries showed high seroprevalence in the elderly. In Finland, seroprevalence fell below $40 \%$ in early 1940s, which approximately coincides with the end of the war in that country.

HAV IgG antibodies pass through the placenta to newborns providing them with protective immunity. 
Usually maternal antibodies disappear by age 6 months, after which children become susceptible, and are at significant risk of infection in an area with endemic circulation of HAV. The susceptibility of newborns was demonstrated here by comparing Romania and Finland. In Romania, the high seroprevalence in women of childbearing age was reflected by the presence of maternally acquired antibodies in the majority of infants. In Finland, the susceptibility in women of childbearing age was high, leading to low seroprevalence in newborns.

The high susceptibility to HAV in young and middle-aged adults demonstrated in this study for most of the participating countries is reflected by numerous reports of outbreaks in both high-risk groups and the general population in Europe. Outbreaks in IDUs have occurred, e.g. in England [18], Finland [19], Italy [20], and The Netherlands [21], and in MSM, e.g. in Denmark [22], Norway [23], and Spain [24]. Outbreaks related to contamination from food and/or food handlers have been reported, e.g. in Belgium [25], Germany [26], Finland [27] and Italy [28]. Travellers to endemic areas are typical risk groups in countries with high susceptibility. Onward transmission after recent travel to an endemic area is occasionally seen in countries with low endemicity [29-32]. Community-wide outbreaks, often related to poor hygienic conditions have been reported, e.g. in Bulgaria, Italy, Latvia, and Slovakia [33-38]. It is evident that vaccination of risk groups in countries with high susceptibility of young and middle-aged adults needs to be continued.

Previous reports suggest a changing epidemiology of HAV in Southern Europe, with outbreaks in young adults due to their increasing susceptibility to HAV $[39,40]$. Our study suggests this phenomenon for both Italy and Malta. While those aged $\geqslant 30$ years still show a low susceptibility to HAV, children and young adults already show a high susceptibility in these two countries.

All other countries except Romania offer HAV vaccination to various high-risk groups. There is a degree of variability between countries (Table 2) as to the targeted groups, related to occupation (e.g. healthcare workers), lifestyle (e.g. travellers, MSM, and IDUs), and underlying medical condition (e.g. haemophiliacs). The policy of all countries except Belgium, Italy, and Malta also included immunization as an outbreak control measure (Table 2).

In conclusion, serosurveys can be used to inform HAV vaccine policy of countries. Romania can be characterized as an area with intermediate HAV endemicity, for which, according the WHO position [13], a nationwide vaccination programme should be considered. All other countries participating in this study are areas of low endemicity, in which targeted vaccination of high-risk groups needs to be continued, in accordance with the WHO recommendation. We have further demonstrated here the continuously changing epidemiology of HAV across Europe. Good surveillance systems need to be maintained to monitor these trends, and to implement the appropriate HAV immunization policies.

\section{ACKNOWLEDGEMENTS}

This work was funded by a grant from DG X11 of the European Union under contract QLK2-CT-200000542 (concerted action). We thank Dr Wulf Thierfelder for help in the collection of German data, $\mathrm{Mr}$ Zisis Moschidis (Greece) for excellent technical assistance in the preparation of the HAV standardization panel, and Dr Viviane Bremer for helpful comments and intellectual input to the manuscript. S.K. is affiliated as a Fellow in the EUPHEM programme, which is developed and endorsed by the establishment of a Collaborative Network of European Laboratories for Outbreak Assistance and Support, coordinated by the European Network for Diagnostics of 'Imported' Viral Diseases (ENIVD-CLRN) and the ECDC.

\section{DECLARATION OF INTEREST}

None.

\section{REFERENCES}

1. Brown GR, Persley K. Hepatitis A epidemic in the elderly. Southern Medical Journal 2002; 95: 826-833.

2. Nothdurft HD. Hepatitis A vaccines. Expert Review of Vaccines 2008; 7 : 535-545.

3. Frosner GG, et al. Antibody against hepatitis A in seven European countries. I. Comparison of prevalence data in different age groups. American Journal of Epidemiology 1979; 110: 63-69.

4. Jacobsen KH, Koopman JS. The effects of socioeconomic development on worldwide hepatitis A virus seroprevalence patterns. International Journal of Epidemiology 2005; 34: 600-609.

5. Beran J, Douda P, Rychly R. Seroprevalence of viral hepatitis A in the Czech Republic. European Journal of Epidemiology 1999; 15: 805-808. 
6. Broman M, et al. Epidemiology of hepatitis A in Finland in 1990-2007. Journal of Medical Virology 2010; 82: 934-941.

7. Gay NJ, et al. Age-specific antibody prevalence to hepatitis A in England: implications for disease control. Epidemiology and Infection 1994; 113: 113-120.

8. Moschen ME, et al. Hepatitis A infection: a seroepidemiological study in young adults in North-East Italy. European Journal of Epidemiology 1997; 13: 875-878.

9. Mossong J, et al. Seroepidemiology of hepatitis A and hepatitis B virus in Luxembourg. Epidemiology and Infection 2006; 134: 808-813.

10. Thierfelder W, et al. Prevalence of markers for hepatitis $\mathrm{A}, \mathrm{B}$ and $\mathrm{C}$ in the German population. Results of the German National Health Interview and Examination Survey 1998. European Journal of Epidemiology 2001; 17: 429-435.

11. Vranckx R, Jacques P, Moens G. Prevalence of hepatitis A antibodies in a large sample of Belgian health care workers. Infection 1999; 27: 256-258.

12. Jacobsen KH, Koopman JS. Declining hepatitis A seroprevalence: a global review and analysis. Epidemiology and Infection 2004; 132 : 1005-1022.

13. World Health Organization. Hepatitis A vaccines. Weekly Epidemiological Record 2000; 75: 38-44.

14. Anastassopoulou CG, et al. The European SeroEpidemiology Network 2 (ESEN2): standardization of assay results for hepatitis A virus (HAV) to enable comparisons of seroprevalence data across 15 countries. Epidemiology and Infection 2009; 137: 485-494.

15. Kafatos G, et al. Model selection methodology for interlaboratory standardisation of antibody titres. Vaccine 2005; 23: 5022-5027.

16. Quoilin S, et al. A population-based prevalence study of hepatitis A, B and C virus using oral fluid in Flanders, Belgium. European Journal of Epidemiology 2007; 22: 195-202.

17. Stroffolini T, et al. Baseline seroepidemiology of hepatitis A virus infection among children and teenagers in Italy. Infection 1991; 19: 97-100.

18. O'Donovan D, et al. An outbreak of hepatitis A amongst injecting drug users. Epidemiology and Infection 2001; 127: 469-473.

19. Leino T, et al. Hepatitis A outbreak amongst intravenous amphetamine abusers in Finland. Scandinavian Journal of Infectious Diseases 1997; 29: 213-216.

20. Spada E, et al. An outbreak of hepatitis A virus infection with a high case-fatality rate among injecting drug users. Journal of Hepatology 2005; 43 : 958-964.

21. Tjon GM, et al. An outbreak of hepatitis A among homeless drug users in Rotterdam, The Netherlands. Journal of Medical Virology 2005; 77: 360-366.

22. Mazick A, et al. Hepatitis A outbreak among MSM linked to casual sex and gay saunas in Copenhagen, Denmark. Eurosurveillance 2005; 10: 111-114.

23. Stene-Johansen K, et al. An outbreak of hepatitis A among homosexuals linked to a family outbreak. Epidemiology and Infection 2002; 129: 113-117.
24. Tortajada C, et al. Outbreak of hepatitis A among men who have sex with men in Barcelona, Spain, September 2008-March 2009. Eurosurveillance 2009; 14: 19175.

25. Robesyn E, et al. An outbreak of hepatitis A associated with the consumption of raw beef. Journal of Clinical Virology 2009; 44: 207-210.

26. Schenkel K, et al. Outbreak of hepatitis A in two federal states of Germany: bakery products as vehicle of infection. Epidemiology and Infection 2006; 134: 1292-1298.

27. Pebody RG, et al. Foodborne outbreaks of hepatitis A in a low endemic country: an emerging problem? Epidemiology and Infection 1998; 120: 55-59.

28. Prato R, et al. An outbreak of hepatitis A in Southern Italy: the case for vaccinating food handlers. Epidemiology and Infection 2006; 134: 799-802.

29. Gervelmeyer A, et al. An outbreak of hepatitis A among children and adults in Denmark, August 2002 to February 2003. Epidemiology and Infection 2006; 134: 485-491.

30. Rajaratnam G, et al. An outbreak of hepatitis A: school toilets as a source of transmission. Journal of Public Health Medicine 1992; 14: 72-77.

31. Richardus $\mathbf{J H}$, et al. Seroprevalence of hepatitis A virus antibodies in Turkish and Moroccan children in Rotterdam. Journal of Medical Virology 2004; 72: 197-202.

32. Frank C, et al. Major outbreak of hepatitis A associated with orange juice among tourists, Egypt, 2004. Emerging Infectious Diseases 2007; 13: 156-158.

33. Hrivniakova L, Slacikova M, Kolcunova S. Hepatitis A outbreak in a Roma village in eastern Slovakia, August-November 2008. Eurosurveillance 2009; 14: 19093.

34. Kojouharova M, Editorial team. Current outbreak of hepatitis A in Bulgaria, 2006. Eurosurveillance 2006; 11 : E061005.1.

35. Perevoscikovs J, et al. Community-wide outbreak of hepatitis A in Latvia, in 2008. Eurosurveillance 2008; 13: 18995.

36. Pontrelli G, et al. Epidemiological and virological characterization of a large community-wide outbreak of hepatitis $\mathrm{A}$ in southern Italy. Epidemiology and Infection 2008; 136: 1027-1034.

37. Prikazsky V, et al. Interruption of an outbreak of hepatitis A in two villages by vaccination. Journal of Medical Virology 1994; 44: 457-459.

38. Vantarakis A, et al. An outbreak of hepatitis A in Roma populations living in three prefectures in Greece. Epidemiology and Infection 2010; 138: 10251031.

39. Stroffolini T, et al. An outbreak of hepatitis A in young adults in central Italy. European Journal of Epidemiology $1990 ; 6$ : 156-159.

40. Lopalco PL, et al. Determinants of acquiring hepatitis A virus disease in a large Italian region in endemic and epidemic periods. Journal of Viral Hepatitis 2005; 12: 315-321. 